\title{
Morphological Analysis of Micro-fibrillated Cellulose from Different Raw Materials for Fiber Plastic Composites
}

\section{Messiry ME*}

Textile Department, Faculty of Engineering, Alexandria University, Alexandria, Egypt

\begin{abstract}
Polymer nanocomposites have attracted great interest during current years. Cellulose micro-fibrils may be function as biodegradable Nano fibrils in high performance composites. The production of Nano-scale cellulose fibers and their application in composite materials has gained increasing attention due to their high strength and stiffness combined with low weight, biodegradability and renewability. Adding small amounts of cellulose-based fillers to thermoplastic matrix polymers usually enhances the mechanical properties. However, the development of fully biodegradable nanocomposites is still a challenging area. Many researchers investigated production of micro cellulose microfibers through various methods. The most important and widely used methods for cellulose Nano fibers isolation are Chemical method (CM), Mechanical methods, Physical methods, Using microwave, Biological and High-pressure homogenizer. CM process is easier than milling process (MM) by which material is reduced from a large size to a smaller size 'top-down'. In this work, a motor driven mechanical rotary microtome sheering device was used to produce microfibrillated cellulose (MFC) particles from different types of cotton fibers and cotton waste, as well as flax. The morphological properties of the cellulose particles were investigated by means of scanning electron microscopy. Final length distribution of cellulose particles was determined. It was found that the maximum number of fibers was observed in the range from 0.5 to 2 microns with average aspect ratio 1.6. Depending on the source of the fibers, the particles with a diameter of $20-500 \mathrm{~nm}$ were observed.
\end{abstract}

Keywords: Fiber plastic composites; Fiber-engineering thermoplastic; Mechanical milling; Cellulose nano-particles; Microfibrillated Cellulose (MFC); Polymer-Matrix composites

\section{Introduction}

Cellulose is the most valued natural biopolymer, which is renewable, as well as biodegradable. As a renewable material, cellulose and its derivatives have been widely studied, focusing on their biological, chemical, as well as mechanical properties.

The production of nano-scale cellulose fibers and their application in composite materials has gained increasing attention due to their high strength and stiffness combined with low weight, biodegradability and renewability [1-7].

The nanotechnology has drawn much attention since the beginning of this century as the critical technology to advance industrial outputs. Developing commercial applications of nanotechnology, the Nanosized particles play a significant role because of their unique functional properties. The nanoparticle technology is expected to further develop rapidly in all the industries handling fine particles in the near future [8-12]. Cellulose nanofibers have many advantages comparing with the inorganic fibers, some of the most relevant being the following: low density, renewable sources, biodegradability.

The main reason in using cellulose nanofibers in composite materials is due to the potentially high stiffness of the cellulose fibers for reinforcement. This property can be achieved with the reducing amount of amorphous material by breaking the structure of the plant in individualized nanofibers with high crystallinity [12].

Growing interest has been focused on biodegradable polymers based materials cellulose microfiber. In the recent years, there has been much interest in the development composite materials fiber-plastic for various applications. One reason is the potential for significant improvements in mechanical properties of fiber-plastic composites (FPC) for use as new materials due to the abundance, low cost, and its processability. One of the famous applications is the use of wood as filler, wood flour, with a low length to-diameter (L/D) ratio 3.3 to 4.5 .
Fiber length and distribution play important role in the processing and mechanical performance of fiber-based composites [13]. Julson et al. [14] studied the mechanical properties of wood-plastic composites made with different loads and sizes of pine flour in a HDPE matrix using an injection-molding process. Compared to fiber proportion, size of screened particles showed no significant impact on mechanical properties of the composite materials. In terms of processing, Yam et al. [15] suggested that mechanical properties and fiber length are sensitive to extrusion parameters such as screw configuration and compounding temperature. Short fibers resulted in better mechanical properties than long fibers, water absorption and volumetric swelling increased with fiber length. Increasing fiber length had beneficial effects on tensile, flexural modulus of elasticity and toughness of woodplastic composites. A decrease in the MOR was observed with the addition of wood fibers into the thermoplastic, but this effect could be minimized by using long fibers. Migneault et al. [16] studied the effect of fiber length of basalt fiber on mechanical properties of the fabricated composites. The length of reinforced fibers plays a significant impact on some mechanical properties, modulus of elasticity, breaking elongation and the impact strength of fiber reinforced composites. Several studies emphasize the effect of fiber length and fiber orientation [17-19] on mechanical properties of the fabricated composites. The development of starch composite materials filled with nano/microsized rigid particles has attracted both scientific and industrial interest, in case of the rice

*Corresponding author: Messiry ME, Textile Department, Faculty of Engineering, Alexandria University, Alexandria, Egypt, E-mail: mmessiry@yahoo.com

Received July 21, 2014; Accepted August 25, 2014; Published September 07 2014

Citation: Messiry ME (2014) Morphological Analysis of Micro-fibrillated Cellulose from Different Raw Materials for Fiber Plastic Composites. J Textile Sci Eng 4: 166. doi:10.4172/2165-8064.1000166

Copyright: (C) 2014 Messiry ME. This is an open-access article distributed under the terms of the Creative Commons Attribution License, which permits unrestricted use, distribution, and reproduction in any medium, provided the original author and source are credited. 
starch (RS) films reinforced with microcrystalline cellulose from palm pressed fiber (MCPF). The incorporation of MCPF into rice starch films provided an improvement of water resistance for the rice starch films. In bio-composite films, rice starch film/MCPF increased tensile strength from 5.16 MPa for pure rice starch film to $44.23 \mathrm{MPa}$, but decreased in elongation at the break of composites [20].

Qiuju Wu [21] study emphasizes on strong nanofibril-polyurethane interaction at the interface, and corresponding effects on physical network structure, the present nanocomposites have large strainto-failure. At high strains, cellulose nanofibrils, as well as polymer molecules, become strongly reoriented in the loading direction, providing additional stiffening.

The poly-lactic acid is a versatile, natural based plastic which has got its potential in many applications, such as medical, drug delivery, textiles or packaging applications [22]. However, PLA is too brittle for many applications, softens at relatively low temperatures, around 50 $60^{\circ} \mathrm{C}$, has worse water vapour and gas barrier properties compared to commercial polymers. To extend the application field, the improvement of its properties (barrier, thermal, mechanical) is required. One of the promising materials to improve these properties of the PLA can be addition of the cellulose particles.

The review of the literature shows that the need of nano/micro particles with the particular size depends on the final applications; hence it plays a decisive role on composite properties.

The production of Nano-scale cellulose fibers and their application in composite materials has gained increasing attention due to their high strength and stiffness combined with low weight, biodegradability and renewability $[1,23,24]$. The most important and widely used methods for cellulose Nano fibers isolation are Chemical method (CM), Mechanical methods, Physical methods, Using microwave, Biological and High-pressure homogenizer. CM process is easier than milling process (MM) by which material is reduced from a large size to a smaller size 'top-down'. Milling may involve breaking up material. Milling is generally done by mechanical means, including attrition, compression, and impact. Impact mills include the ball mill, which has media that tumble and fracture the material. Shaft impactor causes particle-to-particle attrition and compression [4]. Furthermore, this method needs long time and several passes.

The production of MFC by fibrillation of cellulose fibers into Nanoscale elements requires intensive mechanical treatment. However, depending upon the raw material and the degree of processing, chemical treatments may be applied prior to mechanical fibrillation. These chemical processes are aimed to produce purified cellulose, such as bleached cellulose pulp, which can then be further processed. There are also examples with reduced energy demand in which the isolation of cellulose micro-fibrils involves enzymatic pre-treatment followed by mechanical treatments [2].

Mechanical processes, such as high-pressure homogenizers, grinders/refiners cryo-crushing, high intensity ultrasonic treatments, and micro-fluidization have been used to extract cellulose fibrils from WF, PF, MCC, tunicate, algae, and bacterial source materials. In general, these processes produce high shear that causes transverse cleavage along the longitudinal axis of the cellulose micro-fibrillar structure, resulting in the extraction of long cellulose fibrils, termed micro-fibrillated cellulose (MFC). Typically, cellulose materials are run through the mechanical treatment several times (i.e., number of passes). After each pass, the particles are generally smaller, more uniform in diameter, but have increased mechanical damage to the crystalline cellulose.
A filtration step is included to remove the larger unfibrillated and partially fibrillated fractions. In addition, these mechanical processes can be followed by chemical treatments to either remove amorphous material or chemically functionalize the particle surface [6]. Cellulose Nano-fibers would be prepared from microcrystalline cellulose (MCC) by application of a high pressure homogenizer (137.89 $\mathrm{MPa})$ and treatment consisting of different passes $(0,1,2,5,10,15$ and 20) [11].

The potential of cellulose Nano-fibrils as reinforcement provides a new direction for the development of value-added novel composites. These cellulose Nano-fibrils have been extracted from cell walls by a chemical $[2,7,8]$ or mechanical treatment $[9,24]$ and combination of these treatments [6]. Cellulose whiskers from cellulosic materials were prepared by hydrochloric acid and sulfuric acid hydrolysis, and weblike cellulose Nano-fibrils were obtained by refining and homogenizing action. Cellulose Nano-fibrils with diameters below $100 \mathrm{~nm}$ were isolated by a chemical or mechanical treatment. Mechanical treatment with acid hydrolysis results in even finer cellulose Nano-fibril structures with diameters below $50 \mathrm{~nm}$. Microcrystal cellulose (MCC) was used as raw material for the preparation of nanofibers, starting with MCC of about 20 um.

A fundamental mechanism of the high-pressure homogenizer is to bombard a fluid stream against itself within interaction chambers of fixed geometry at very high energy, resulting directly in the breakup and dispersion of the slurry. High pressure, high velocity and a variety of forces on the fluid stream are capable of generating shear rates within the product stream, reducing particles to Nano-scale. A pass through the homogenizer was performed through the interaction chambers of 120 and 87 um 20,000 psi for about $1 \mathrm{~min}$. In order to fibrillate MCC, pass numbers were $0,1,2,5,10,15$ and 20 [11].

The MCC fibrils have approximately the particle sizes of $10 \mathrm{um}$ length and $2 \mathrm{~mm}$ diameter (aspect ratio of around 5). After further treatment to 20 passes, these small bundles were additionally split into thinner fiber bundles.

In this work, a motor driven mechanical rotary shearing microtome device is used to slice thin layers of fibers aggregating to produce microfibril cellulose (MFC). Samples of different types of cotton fibers and its waste, as well as flax, have been tested. The morphology of the microcellulose particles and its length distribution were investigated.

\section{Material and Methods}

\section{Material}

Four samples of raw cotton and cotton waste (carding flat stripes, under taker in waste, ginning waste, cotton wool) were cleaned by processing through the carding machine to produce web, which further was laid in several layers to form a sheet of weight $200 \mathrm{~g} / \mathrm{m}^{2}$. The cotton wool samples are commercial product. Flax fibers were also hand laid to form a sheet with the same areal density.

In order to prepare a sheet of fibers which can be sheared easily, it is essential to solidify the fibers structure to form the uniform sheet of randomly arranged fibers.

Cotton sheet is pressed, after soaking in water based natural glue, to remove the excess liquid and dried in oven at $110^{\circ} \mathrm{C}$ till it forms a solid sheet suitable to be sliced on cutting machine. Figure 1 demonstrates photo of the sheet that points toward the random arrangement of the fibers. 
Citation: Messiry ME (2014) Morphological Analysis of Micro-fibrillated Cellulose from Different Raw Materials for Fiber Plastic Composites. J Textile Sci Eng 4: 166. doi:10.4172/2165-8064.1000166

Page 3 of 7

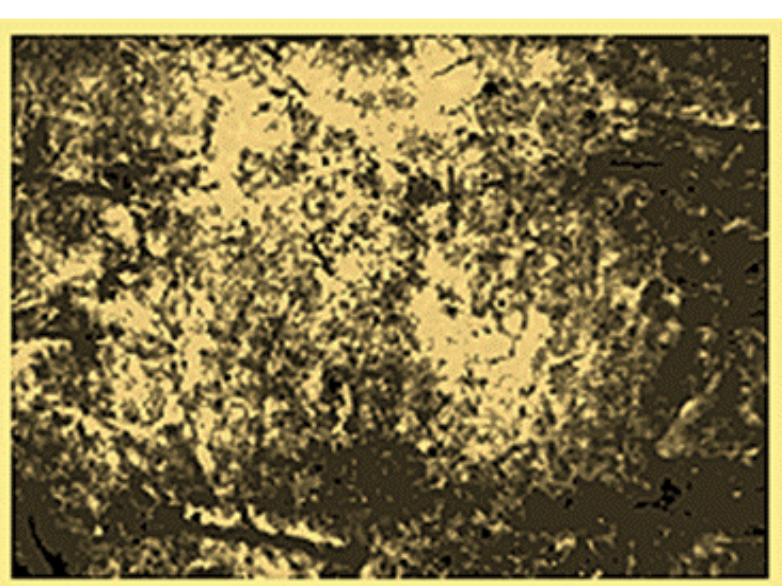

Figure 1: cotton sheet.

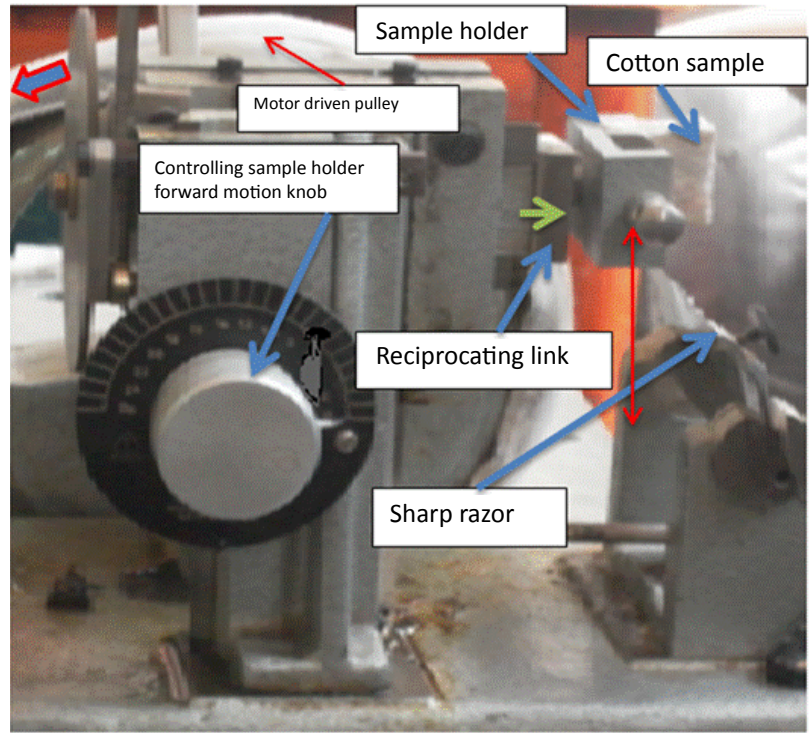

Figure 2: Mechanical rotary microtome.

\section{Mechanical slicing method}

Mechanical slicing method is simpler than milling process (MM) by which material is reduced from a large size to a smaller size 'topdown'. Milling may involve breaking up material. Milling is generally done by mechanical means, including attrition, compression, and impact. Impact mills include the ball mill, which has media that tumble and fracture the material.

In this work, a mechanical rotary microtome device was used to produce microfibrillated cellulose (MFC) nanoparticle. Cutting sections are obtained in different thickness by mechanically operated crank through a knurled knob in front of the instrument. The knurled knob is graduated in microns for feed setting and ready reference. A detent click action ensures positive adjustments in one micron increment. The microtome is modified to be motor driven to insure the continuous cutting of the fiber. Figure 2 shows the parts of mechanical rotary microtome used. To remove the larger unfibrillated and partially fibrillated fractions, the sliced fibers were filtrated using sieving machines with the fine mesh vibratory sieves, screening down to 5-20 microns.

\section{Results and Discussions}

\section{Relation between cuter displacement and particle length}

Here a question arises; what is the best length of the fibers suitable to get the shortest fiber length? The mechanical cutter can be adjusted to the range of one micron. Can the arrangement of the fibers result in less fiber length?

Figure 3 illustrates the different categories of fiber arrangement in the compressed sheets. During cutting of the layers with the cutting distance $d l$, the cut fiber length $d l_{\mathrm{f}}$ will vary according to the fiber configuration.

The probability of getting more particles of length $d \boldsymbol{h}_{f}$ less than cutting length $d l$ is higher in the case of the entangled fiber arrangement in the fibrous assembly. The shorter the fiber is the higher will be probability to get more nanoparticles. However, the layout of the fibers is lying in three dimensions, as shown in Figure 4, consequently the length of the particles will be longer than cutting length $\Delta \mathrm{h}_{\mathrm{f}}$ depending on the packing density.

The packing density of different fibrous assemblies, given by Necker

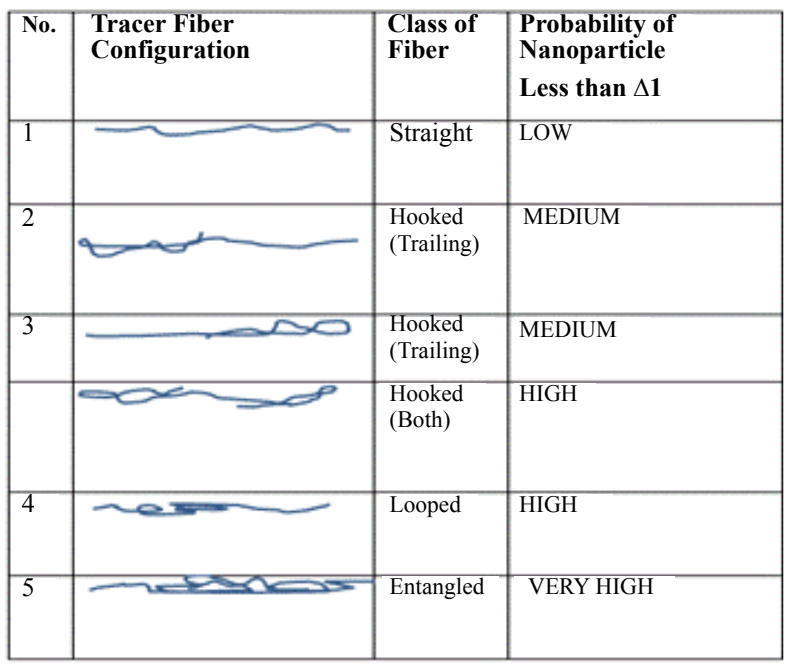

Figure 3: Classification of fiber in fibrous assembly.

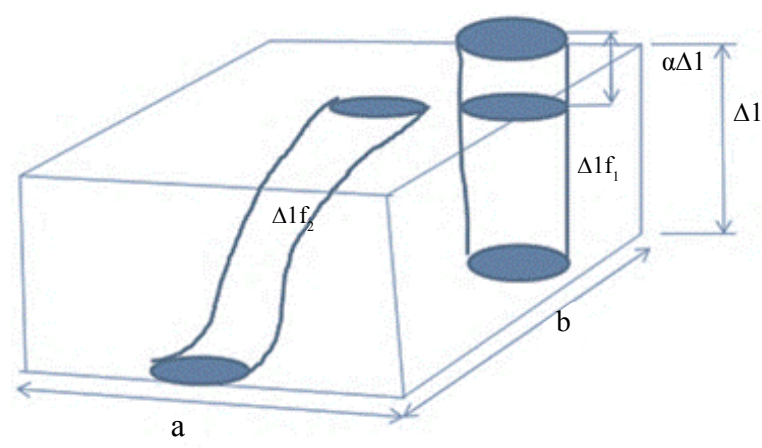

Figure 4: Fiber segment in an elementary section of fibrous assembly. 


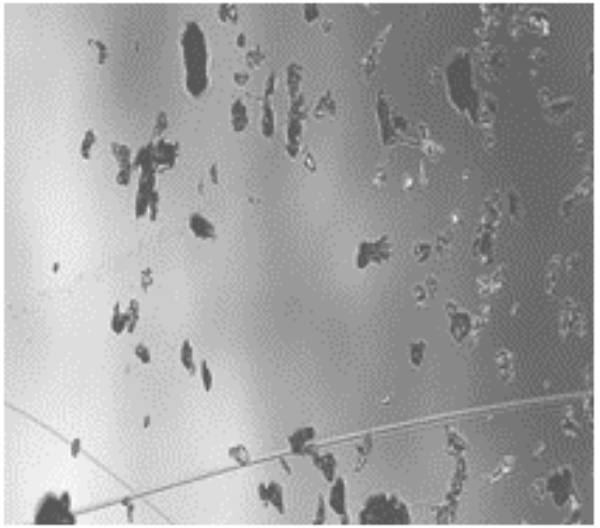

Figure 5: Sliced cellulosic particles shapes.

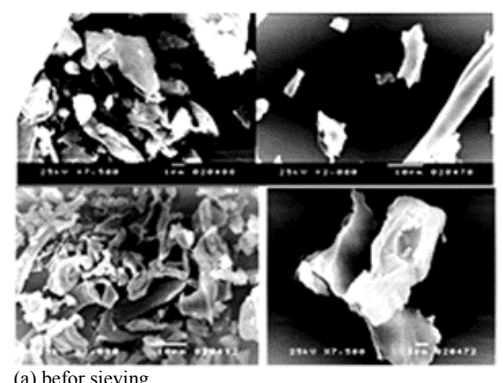

(a) befor sieving
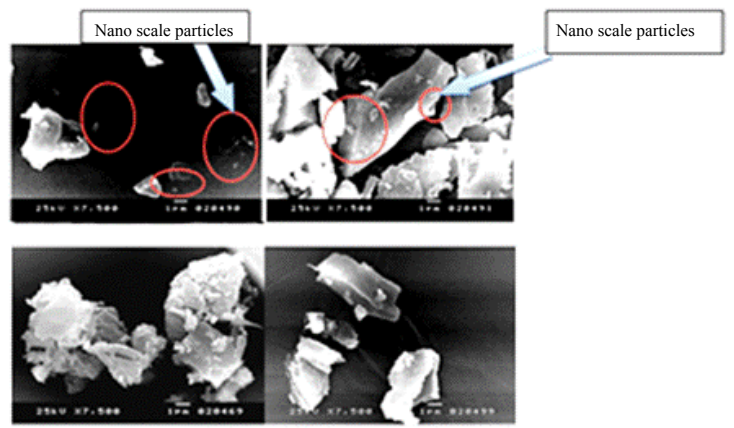

(b) after sieving

Figure 6: Morphology of fiber particles observed with a scanning electron microscope (SEM) before and after sieving.

and Ibrahim [25], varied between 0.03 for sliver to 0.6 for combed yarns. Figure 4 shows that, if the cutting increment is $(d l)$, then the cut fiber length can be determined from the following equation;

$$
d h f=d h *(S f / S l) /\left(\frac{\rho^{*}}{\rho 1}\right)
$$

Where, $\rho^{*}$ limited packing density $(0.907), \rho_{1}$ fiber density (cotton $\left.1520 \mathrm{Kg} / \mathrm{m}^{3}\right)$,

$S f$ total sectional area of all fibers in the cross-section area $(\mathrm{ab})$, and $S l$ total the cross-section area $(\mathrm{ab})$.

The above equation does not take into consideration fiber orientation inside the element; so the fiber of length $L$ will have a number of particles of length $d \boldsymbol{h}_{\boldsymbol{f}}$ (L/ $d \boldsymbol{h}_{f}+$ residual length less than $d \boldsymbol{h}_{f}$ ). If the fiber is not straight, the number of particles of length less than $d \boldsymbol{h}_{f}$ is increased. Residual length $\Delta \boldsymbol{l}$ has maximum length $d \boldsymbol{h}_{f}$, that is;

$$
0=\Delta_{l} \leq d \boldsymbol{h}_{f}
$$

To increase the residual lengths which are less than $d \boldsymbol{h}_{f}$ fibers of shorter length should be used. Moreover, the orientation coefficient of the fibers should be less than one as possible, hence random orientation is recommended.

Depending on the above analysis to increase the probability of getting nanoparticles, the sliced sample should consists of multicompressed layers of as small thickness as possible, made of short entangled fibers.

\section{Characterization of sliced cellulosic particles}

Figure 5 illustrates the nature of the particles attained by the slicing process. It is obvious that particle shape takes different shapes which can be classified as; rounded irregular, elongated elliptical irregular, triangle irregular in cross section.

Analysis of the cellulosic particles size using SEM: The morphology of fiber particles was observed with a scanning electron microscope SEM which displayed nano-scaled particles, marked by red circle, as well as micro scaled ones. Most of the particles are micro fibers, although some aggregates of nano particles are still visible, and the shape of the particle is not regular but with small aspect ratio. The sieving results in more filtration of the particles from large scale fibers. Figures $6 \mathrm{a}$ and $6 \mathrm{~b}$ shows SEM micrographs of some tested samples.

Evaluation of the particles size: In order to determine the particle dimensions, edge detection is used to trace the edges of the particles cross section in the photo, which projected on the computer monitor screen. Once the edges are completely outlined, the next step is to use scan lines interactions to determine the horizontal and vertical diameters. Knowing the picture resolution, we can determine the particle diameter.

Figure 7 illustrates the histogram of a sample of 700 particles. The value of cutting length $\Delta \mathrm{h}_{\mathrm{f}}$ is 2 micron. The analysis of the histogram of the sample particles length in micron evidences that $48 \%$ of the particles have a length less than 2 micron which is the sum of residual length of the fibers with a tendency be skewed to the right. The mean

Histogram and Fitted Normal Density

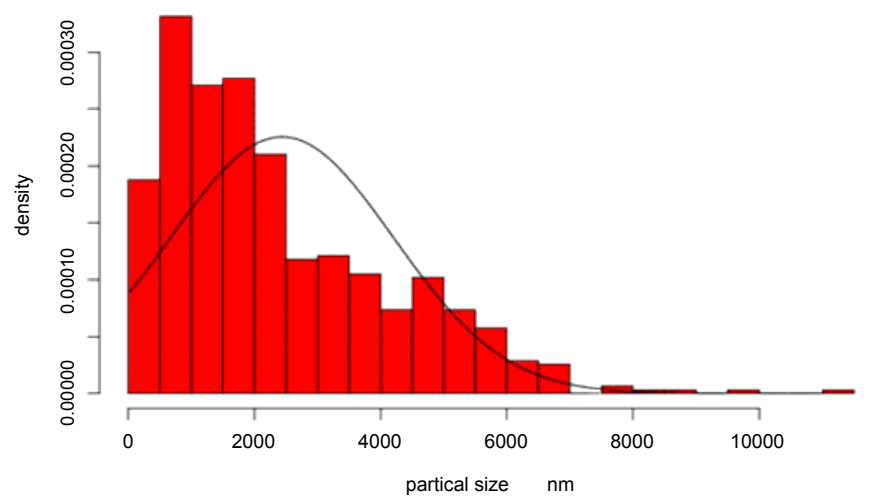

Figure 7: Histogram of the cellulose particles distribution. 


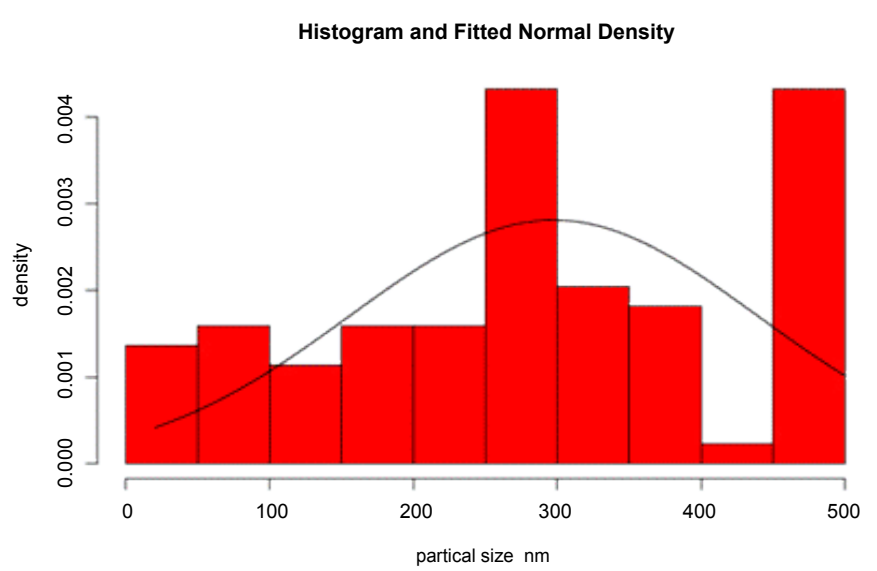

Figure 8: Histogram distribution of the cellulose particles of size equal to or less than $500 \mathrm{~nm}$.

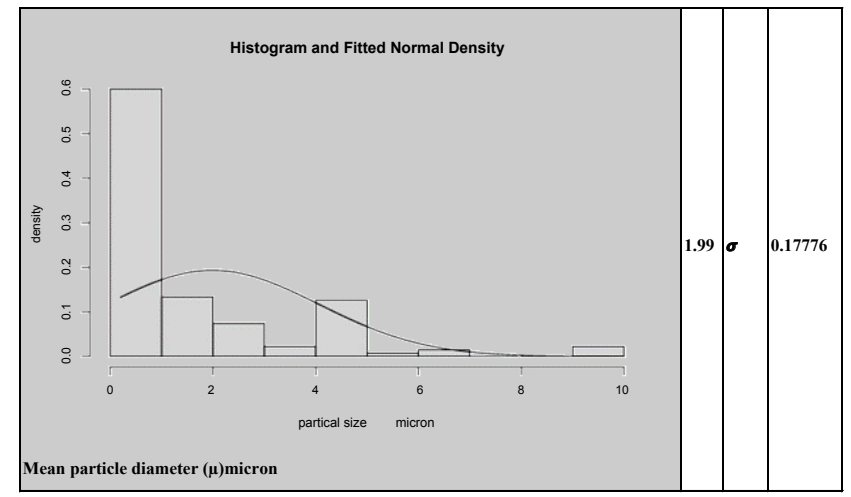

Histogram distribution of the cellulose particles size of the different fibers waste

Figure 9a: Carding Flat stripe.

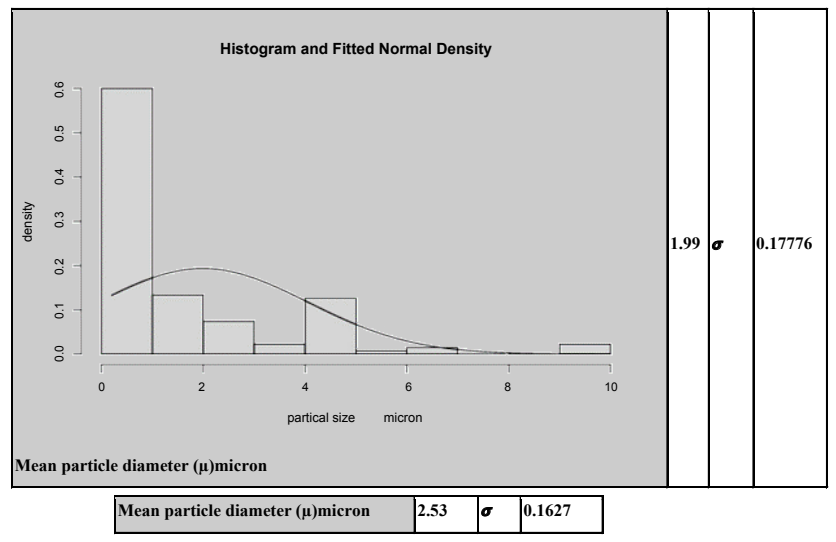

Histogram distribution of the cellulose particles size of the different fibers waste

Figure 9b: Under Taker in waste.

value of particle length is $2437 \mathrm{~nm}$ and CV $2.87 \%$ with probability of nano-particles presence, with law aspect ratio of 1.6 in average.

The analysis of the histogram of particle size equal to or less than

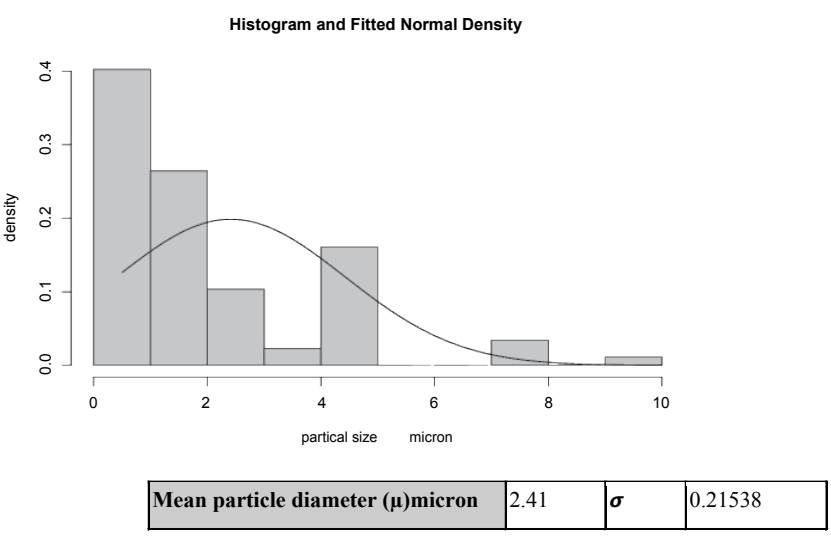

Histogram distribution of the cellulose particles size of the different fibers waste

Figure 9c: Cotton wool.

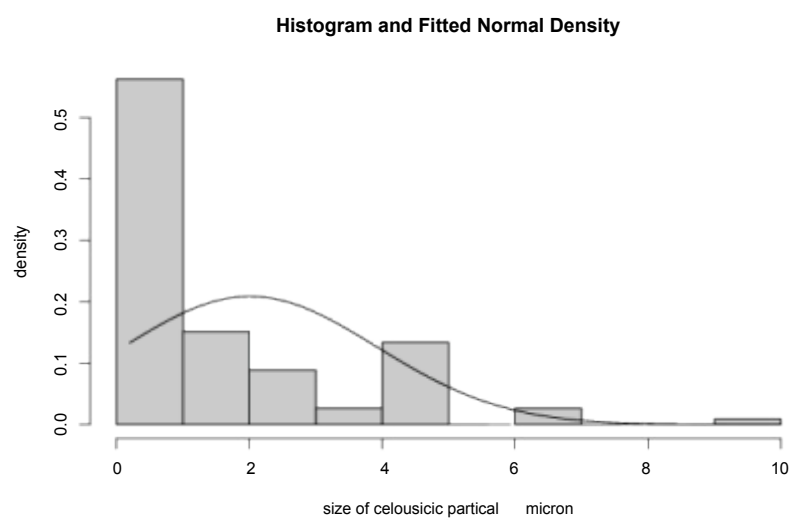

\begin{tabular}{|l|l|l|l|}
\hline Mean particle diameter $(\mu)$ micron & 2.27 & $\sigma$ & 0.1713 \\
\hline
\end{tabular}

Histogram distribution of the cellulose particles size of the different fibers waste Figure 9d: Ginning waste.

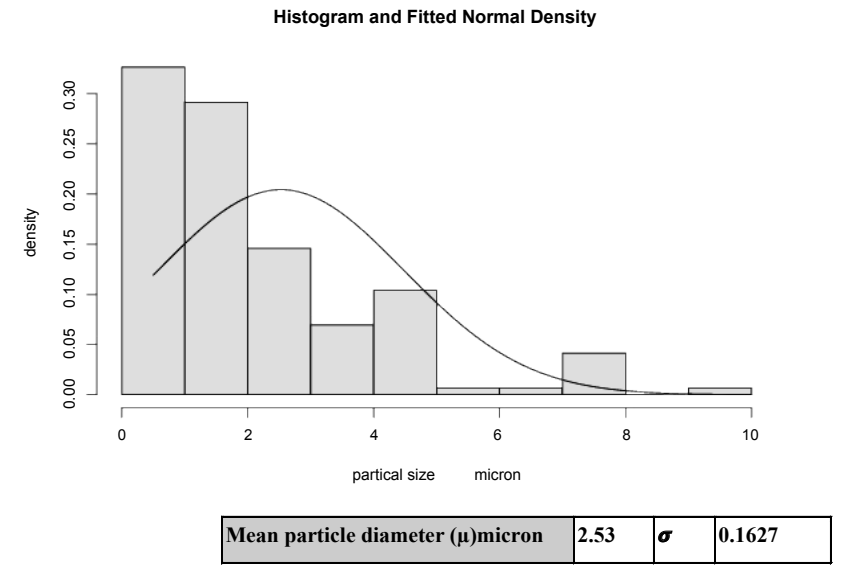

Histogram distribution of the cellulose particles size of the different fibers waste

Figure 9d: Ginning waste. 
Citation: Messiry ME (2014) Morphological Analysis of Micro-fibrillated Cellulose from Different Raw Materials for Fiber Plastic Composites. J Textile Sci Eng 4: 166. doi:10.4172/2165-8064.1000166

Page 6 of 7

\begin{tabular}{|c|c|c|c|c|}
\hline Material type & $\begin{array}{c}\text { Fiber } \\
\text { length }\end{array}$ & $\begin{array}{c}\text { Average } \\
\text { particle size } \\
(\boldsymbol{\mu}) \text { micron }\end{array}$ & $\mathbf{C V} \%$ & $\begin{array}{c}\text { Percentage of } \\
\text { particle length< }(\boldsymbol{\mu}) \\
\text { micron }\end{array}$ \\
\hline Cotton & 32 & 2.64 & 2.87 & $38 \%$ \\
\hline Cotton (flats stripes waste) & 10 & 1.99 & 8.9 & $50 \%$ \\
\hline Cotton (taker-in waste) & 18 & 2.53 & 6.43 & $32 \%$ \\
\hline Cotton wool & 12.5 & 2.41 & 8.92 & $40 \%$ \\
\hline Cotton Ginning waste & 11 & 2.27 & 7.546 & $35 \%$ \\
\hline Flax & 25 & 2.53 & 6.436 & $32 \%$ \\
\hline
\end{tabular}

Table 1: Particle length frequency distribution for different samples.

\section{Particle diameter}

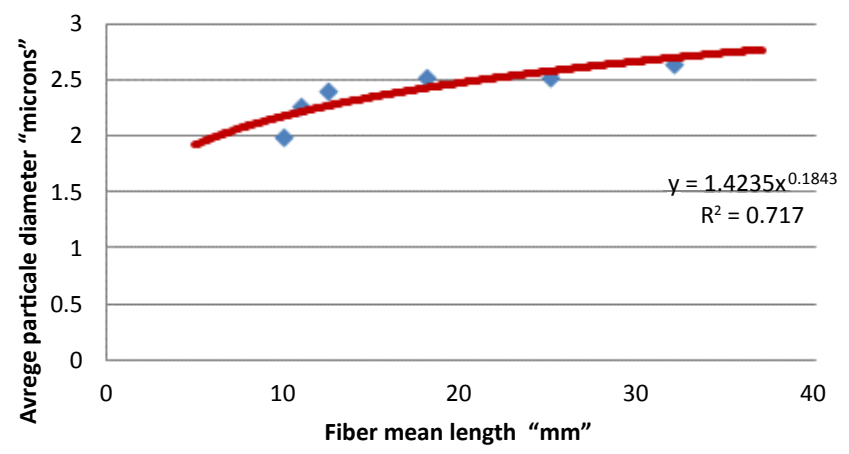

Figure 10: Average particle diameter versus the fiber length.

$500 \mathrm{~nm}$ indicates that the average particle size is equal to $297 \mathrm{~nm}$ and CV 5\%, as given in Figure 8.

Several samples of various types of cotton waste, prepared and sliced by the above described method, were analyzed for particle morphology.

Figures 9a-9e represents histogram distribution of the cellulose particles size of the different fibers waste and also of the flax fibers. Table 1 denotes the length of the different fibers cotton samples as well as the dimensions of the particles in each case, categorizing that the smallest particle size was obtained when flat stripes or cotton wool were used, hence more than $50 \%$ of the particles had size less than one micron.

Figure 10 illustrates the effect of the fiber length in the different samples on the diameter of the particles produced, which coincides with the conclusions of the theoretical work by the recommendation to start with as short fibers as possible to produce fine particles.

\section{Conclusion}

This work provides a simple method for production of microcellulosic particles. The use of fiber slicing method turns to be more productive than the other mechanical methods and capable to complete fibrillation of the bulk fibers at nano/micro sized rigid particles. To increase the probability of getting nanoparticles, the sample should consist of compressed layers of as small thickness as possible made of short entangled fibers. The experimental work confirmed that cotton wool and flat stripes samples gave the best results concerning the size of the particles.

\section{References}

1. Peng BL, Dhar N, Liu HL, Tam KC (2011) Chemistry And Applications Of Nanocrystalline Cellulose And Its Derivatives. A Nanotechnology Perspective the Canadian Journal of Chemical Engineering 89:1191-1206.

2. Siro I, Plackett D (2010) Microfibrillated cellulose and new nanocomposite materials. Cellulose 17: 459-494.
3. Yokoyama T, Huang CC (2005) Nanoparticle Technology for the Production of Functional Materials, KONA powder and particals 23: 7-17.

4. Miroslawa SA, Janusz K, Tadeuez A (2012) Nanotechnology - Methods of Manufacturing Cellulose Nanofibers. Fibers \& Textiles in Eastern Europe 91:812.

5. Patel BH, Chattopadhyay DP (2007) Nano-particles \& their uses in textiles. The Indian Textile Journal

6. Moon RJ, Martini AL, Nairn J, Simonsen J, Youngblood J (2011) Cellulose nanomaterial review, structure, properties and nanocomposites. Chem Soc Rev 40: 3941-3994.

7. Kalia S, Dufresne A, Cherian BM, Kaith BS, Avérous L, et al. (2011) CelluloseBased Bio- and Nanocomposites, A Review. International Journal of Polymer Science.

8. Frone AN, Panaitescu DM, Donescu D (2011) Some aspects concerning the isolation of cellulose micro- and nano- fibers, UPB Sci Bull, Series B 73: 133152.

9. Henriksson M, Henriksson G, Berglund LA, Lindstro"m T (2007) An environmentally friendly method for enzymeassisted preparation of microfibrillated cellulose (MFC) nanofibers. European Polymer J 43: 3434 3441.

10. Paakko M, Ankerfors M, Kosonen H, Nykanen A, Ahola S, et al. (2007) Enzymatic hydrolysis combined with mechanical shearing and highpressure homogenization for nanoscale cellulose fibrils and strong gels, Biomacromolecules 8: 1934-1941.

11. Lee SY, Chun SJ, Kang IA, Park JY (2009) Preparation of cellulose nanofibrils by high pressure homogenizer and cellulose-based composite films. Journal of Industrial and Engineering Chemistry 15: 50-55.

12. Yadav TP, Yadav RM, Singh DP (2012) Mechanical Milling, a Top Down Approach for the Synthesis of Nanomaterials and Nanocomposites, Nanoscience and Nanotechnology 2: 22-48.

13. Stark NM, Rowlands RE (2003) Effects of Wood Fiber Characteristics on Mechanical Properties of Wood/Polypropylene Composites, Wood Fiber Science 35: 167-174.

14. Julson JL, Subbarao G, Stokke DD, Gieselman HH, Muthukumarappan KJ (2004) Mechanical properties of biorenewable fiber or plastic composites App Polym Sci J 93: 2484-2493.

15. Yam KL, Gogoi BK, Lai CC , Selke SE (1990) Composites from compounding wood fibers with recycled high density polyethylene, Polymer Eng Sci J 30 : 693-699.

16. Migneault S, Koubaa A, Erchiqui F, Chaala A, Englund K, et al. (2008) Effect of Fiber Length on Processing and Properties of Extruded Wood-Fiber/HDPE Composites. Journal of Applied Polymer Science 110: 1085-1092.

17. Amuthakkannan P, Manikandan V Winowlin Jappes JT, Uthayakumar M (2013) Effect Of Fibre Length And Fibre Content On Mechanical Properties Of Short Basalt Fibre Reinforced Polymer Matrix Composites, Materials Physics And Mechanics 161: 107-117.

18. Fu SY, Lauke B (1996) Effect of fiber length and fiber orientation distribution on the tensile strength of short - fiber reinforced polymers, Composite science and technology 56: 1179-1190.

19. Samir M, Alloin F, Gorecki W, Sanchez JY, Dufresne A (2004) Cross linked Nanocomposite Polymer Electrolytes reinforced with cellulose Whiskers. Macromolecules 37: 4839-4844.

20. Wittaya T (2009) Microcomposites of rice starch film reinforced with microcrystalline cellulose from palm pressed fiber. International Food Research Journal 16: 493-500.

21. Wu Q, Henriksson M, Liu X, Berglund LA(2007)A High Strength Nanocomposite Based on Microcrystalline Cellulose, Polyurethane, the American Chemical Society 8: 3687-3692

22. Halász K, Csóka L, Rákosa R (2012) Application of Nano and Micro Sized Cellulose Crystals in Poly/lactic Acid, Int. Scientific Conference on Sustainable Development \& Ecological Footprint, March 26-27, Sopron, Hungary.

23. Perez DDS, Lingua ST, Lavalette A, Barbosa T, Gonzalez I, et al. (2010) Impact of micro/nanofibrillated cellulose preparation on the reinforcement properties of paper and composites films, Int. Conference on Nanotechnology for the Forest Products Industry. 
Citation: Messiry ME (2014) Morphological Analysis of Micro-fibrillated Cellulose from Different Raw Materials for Fiber Plastic Composites. J Textile Sci Eng 4: 166. doi:10.4172/2165-8064.1000166

Page 7 of 7

24. Siro I, Plackett $P(2010)$ Microfibrillated cellulose and new nanocomposite materials: a review. Cellulose 17: 459-494.
25. Necker B, Ibrahim S (2003) Structural Theory of Fibrous Assemblies and Yarns. Publications of Technical University of Liberec 73: 611- 619 